\title{
Innate Receptors Expression by Lung Nociceptors: Impact on COVID-19 and Aging
}

OPEN ACCESS

Edited by:

Lilian Basso,

Toulouse Institute for Infectious and Inflammatory Diseases (INSERM),

France

Reviewed by:

Daniel Gonzalez-Dunia, Institut National de la Santé et de la Recherche Médicale (INSERM),

France

Junting Huang, Zhongshan School of Medicine Sun

Yat-sen University, China

*Correspondence:

Carlos H. Hirok carlos.hiroki@ucalgary.ca Bryan G. Yipp

bgyipp@ucalgary.ca

Specialty section: This article was submitted to Multiple Sclerosis and Neuroimmunology, a section of the journal

Frontiers in Immunology

Received: 29 September 2021 Accepted: 16 November 2021 Published: 16 December 2021

Citation: Hiroki CH, Sarden N, Hassanabad MF and Yipp BG (2021) Innate Receptors

Expression by Lung Nociceptors: Impact on COVID-19 and Aging.

Front. Immunol. 12:785355. doi: 10.3389/fimmu.2021.785355

\author{
Carlos H. Hiroki ${ }^{1,2 *}$, Nicole Sarden ${ }^{1,2}$, Mortaza F. Hassanabad ${ }^{1,2}$ and Bryan G. Yipp ${ }^{1,2 *}$ \\ ${ }^{1}$ Calvin, Phoebe and Joan Snyder Institute for Chronic Diseases, Cumming School of Medicine, University of Calgary, \\ Calgary, AB, Canada, ${ }^{2}$ Department of Critical Care, Cumming School of Medicine, University of Calgary, Calgary, \\ $A B$, Canada
}

The lungs are constantly exposed to non-sterile air which carries harmful threats, such as particles and pathogens. Nonetheless, this organ is equipped with fast and efficient mechanisms to eliminate these threats from the airways as well as prevent pathogen invasion. The respiratory tract is densely innervated by sensory neurons, also known as nociceptors, which are responsible for the detection of external stimuli and initiation of physiological and immunological responses. Furthermore, expression of functional innate receptors by nociceptors have been reported; however, the influence of these receptors to the lung function and local immune response is poorly described. The COVID-19 pandemic has shown the importance of coordinated and competent pulmonary immunity for the prevention of pathogen spread as well as prevention of excessive tissue injury. New findings suggest that lung nociceptors can be a target of SARS-CoV-2 infection; what remains unclear is whether innate receptor trigger sensory neuron activation during SARS-CoV-2 infection and what is the relevance for the outcomes. Moreover, elderly individuals often present with respiratory, neurological and immunological dysfunction. Whether aging in the context of sensory nerve function and innate receptors contributes to the disorders of these systems is currently unknown. Here we discuss the expression of innate receptors by nociceptors, particularly in the lungs, and the possible impact of their activation on pulmonary immunity. We then demonstrate recent evidence that suggests lung sensory neurons as reservoirs for SARS-CoV-2 and possible viral recognition via innate receptors. Lastly, we explore the mechanisms by which lung nociceptors might contribute to disturbance in respiratory and immunological responses during the aging process.

Keywords: sensory neurons, nociceptors, innate receptors, COVID-19, aging, inflammaging, neuroimmune crosstalk 


\section{INTRODUCTION}

\section{The Lungs Are Constantly Exposed to External and Hazardous Threats}

The lungs are responsible for the process of breathing whereby gas exchange occurs between the external air and the bloodstream. Upon contraction of the diaphragm and intercostal muscles, the lungs expand, resulting in the creation of a negative pressure when compared to the external pressure (1). As a result, the air travels through the nose, oropharynx, larynx, trachea, bronchi, and spreads into the several bronchioles inside of the lungs, allowing an extensive area of contact with the alveolar epithelial cell layer (over $70 \mathrm{~m}^{2}$ ) (2). For proper gas exchange, the distance between the alveolar and the vascular compartments must be thin (around $2 \mu \mathrm{m}$ ) as well as soft for efficient gas diffusion through the tissue (3). Furthermore, an average adult breathes thousands of liters of air per day (4); however, the external air is not sterile, carrying particles and pathogens. Therefore, due to the constant exposure of non-sterile air with an extensive and delicate tissue, any insult could reach the lungs and cross the epithelial and interstitial barriers, reaching the bloodstream and causing systemic inflammation. Nevertheless, the combination of lung sensory neuron-triggered reflexes, which expel these threats from the airway, along with a unique immunological niche equipped to rapidly eliminate microbes, guarantees at least some level of protection.

Pulmonary host defense relies on both immune and nervous systems. An efficient immunological milieu composed of patrolling leukocytes, such as alveolar macrophages and neutrophils, clears pathogens in the alveoli and prevents their dissemination into the bloodstream $(5,6)$. In addition, sensory neurons detect external threats and trigger reflexes, such as cough or sneezing, leading to their expulsion (7). These neurons are located throughout the respiratory tract (upper and lower airways) working as "mucosal guards", alerting the central nervous system, and initiating local responses upon detection of insults (8).

\section{LUNG SENSORY INNERVATION}

Sensory neurons are responsible for the detection of harmful external stimuli in the lungs and in the airways, providing inputs to the central nervous system through the vagus nerve and the spinal dorsal root ganglia (DRG) (9). Most of the lung sensory neurons come from the vagal innervation, which can be stratified into the jugular and nodose ganglia. Anatomically, jugular innervation terminates mostly in extrapulmonary sites and reaches the paratrigeminal nucleus whereas nodose neurons innervate most of intrapulmonary sites and communicate with the nucleus of the solitary tract $(8,10)$. This afferent function informs the central nervous system, which in response, coordinates a physiological response. Furthermore, sensory neurons also perform an efferent function through the release of neuropeptides, which triggers local responses (11). A representation of the lung sensory innervation is demonstrated by the Figure 1.

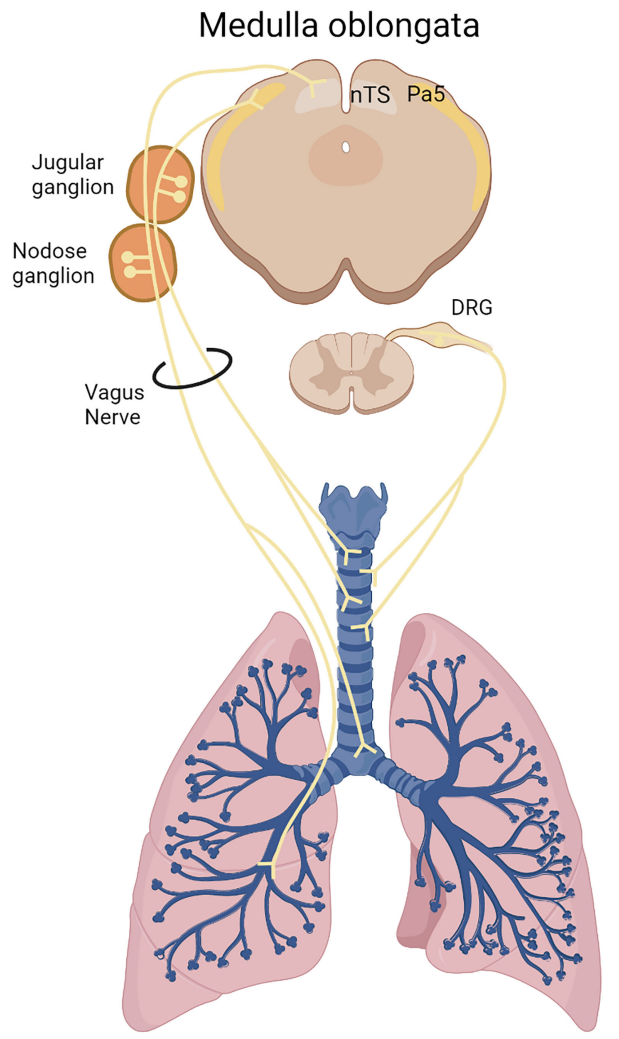

FIGURE 1 | Lung sensory innervation. Sensory neurons innervate the lungs originating in the medulla oblongata via the vagus nerve from the nodose/ jugular ganglia or from the dorsal root ganglion (DRG) in the spinal cord. Nodose neurons innervates most of intrapulmonary sites and communicates with the nucleus of the solitary tract (NTS), whereas jugular neurons innervate most of extrapulmonary sites and reaches the paratrigeminal center (Pa5).

Sensory neurons can be categorized as A-fibers and C-fibers based on physiological properties, production of neuropeptides and speed of conduction. A-fibers are non-peptidergic, myelinated and conduct the electrical pulse with a speed of 5$18 \mathrm{~m} / \mathrm{s}$ (10). Their terminal innervation ends in airway smooth muscle cells and neuroepithelial bodies in the airway epithelium, where they are responsible for the detection of mechanostimuli, such as lung inflation as well as chemical and thermal stimuli (12). C-fibers are unmyelinated and slow-conducting neurons (impulse speed is around $1 \mathrm{~m} / \mathrm{s}$ ) responsible for the detection of thermal, physical and chemical stimuli, such as capsaicin and bradykinin, from extrapulmonary (larynx, trachea and main bronchi) and intrapulmonary tissue (13). Most of the C-fiber neurons express transient receptor potential (TRP) cation channels, such as TRPA1 and TRPV1. These receptors are responsible for the detection of heat, acidosis, osmosis, cold and environmental irritants (14). A summary of the cellular a physiological functions of A- and C- fibers are summarized at Table 1. Upon activation, a calcium influx triggers neuron depolarization, resulting in the action potential firing and releasing the feeling of pain or spiciness to the central nervous system as well as inducing reflexes, such as cough and sneezing (15). 
TABLE 1 | Summary of the key differences and similarities between A- and C-fibers.

\begin{tabular}{|c|c|c|}
\hline & C-fibers & A-fibers \\
\hline Fiber Subtypes & N/A & $A \beta-, A \delta$-fibers \\
\hline Myelination \& Diameter & Unmyelinated and 0.2-1.5 $\mu \mathrm{m}$ & Myelinated and 7-20 $\mu \mathrm{m}$ \\
\hline Conduction Speeds & $0.5-2 \mathrm{~m} / \mathrm{s}$ & $5-20 \mathrm{~m} / \mathrm{s}$ \\
\hline Stimulus & $\begin{array}{l}\text { Chemical Stimuli (eg. Capsaicin, Acidity), } \\
\text { Osmolarity, Temperature changes }\end{array}$ & $\begin{array}{l}\text { Mechanical forces (tissue stretch, punctate } \\
\text { stimuli), Acidity, ATP }\end{array}$ \\
\hline Anatomical Connections & \multicolumn{2}{|c|}{$\begin{array}{l}\text { Intrapulmonary and Extrapulmonary terminations } \rightarrow \text { Dorsal Root Ganglion \& afferent port of Vagus Nerve (Jugular } \\
\text { Ganglion, Nodose Ganglion) } \rightarrow \text { CNS }\end{array}$} \\
\hline Physiological Response & Cough, Bronchoconstriction, Tachypnea & $\begin{array}{l}\text { Cough, Bronchoconstriction \& } \\
\text { Bronchodilation, Tachypnea }\end{array}$ \\
\hline
\end{tabular}

N/A, Not applicable.

Importantly, TRP channels are not alone in their ability trigger sensory neuron activation. Innate receptors present on the cell surface as well as in the cytoplasm allows sensory neuronal activation upon recognition of pathogens or damage-associated molecular patterns (PAMPs and DAMPs, respectively).

\section{INNATE RECEPTORS EXPRESSION BY NOCICEPTORS}

Upon infection and/or injury, immune cells respond to PAMPs/ DAMPs through widely conserved pathogen-recognition receptors (PRRs) such as toll-like receptors (TLR), C-type lectin receptors (CLR), Nod-like receptors (NLR), RIG-I-like receptors (RLR) and cytosolic DNA sensors (CDS). It has become evident that nociceptors can directly recognize pathogens and danger signals by their expression of innate receptors, which can result in pain, itch, hypernociception or in the context of lung nociceptors, the induction of cough. Additionally, sensory neurons can detect immune molecules such as cytokines and antibodies through expression of their respective receptors. Given the abundant distribution of sensory neurons across the lung, they are one of the first cells exposed to insults and their expression of innate receptors poise them for immediate modulation of an inflammatory response. A representation of innate receptors expression in nociceptors is demonstrated by Figure 2.

\section{Toll-Like Receptors}

Toll-like receptors are the best characterized PRR. Each TLR is composed of leucine-rich repeats that mediate recognition, a transmembrane domain and a cytoplasmic domain that initiates downstream signaling (16). TLRs interact with their ligand as a homo or heterodimer which leads to activation of intracellular signaling pathways including MyD88, NF- $\kappa \mathrm{B}$ and MAP kinase pathways resulting in the initiation of an inflammatory response (16). TLRs include 10 receptors in humans (TLR 1-10) and 12 in mice (TLR 1-9, 11-13). TLRs localize in the cell surface or intracellular compartments and recognize various PAMPs. For instance, TLR1 and 2 recognize bacterial lipoproteins, TLR3 recognizes double stranded RNA (dsRNA), TLR4 recognizes LPS, TLR5 recognizes flagellin, TLR7 and 8 sense single stranded RNA and TLR9 recognizes unmethylated CpG motifs (17).

Nociceptors in the DRG and nodose/jugular ganglia are known to express functional TLRs, including TLR2, TLR3, TLR4, TLR5, TLR7, TLR8 and TLR9, extensively reviewed elsewhere (18). Nociceptors have also been shown to couple TLRs noncanonically to ion-channels $(19,20)$. Interestingly, using transcriptomic profiling in nociceptors, TLR4 has found to be the most highly expressed PRR (18). Lipopolysaccharide (LPS) from gram-negative bacteria, the classical TLR4 ligand, is known to directly activate nociceptors through TLR4 resulting in TRPV1 sensitization, calcium influx and neuropeptide release (20). For example, LPS stimulates CGRP release from the vagal ganglia through TLR4 expression in vagal afferents (21). Furthermore, LPS is also known to induce pelvic pain in the context of urinary tract infections in a TLR4-dependent manner (22). In addition, TLR4 expression in nociceptors drove the development of neuropathic pain in female mice, resulting in mechanical hypersensitivity while absent in conditionally depleted mice (23). Moreover, LPS stimulation has been shown to depend on TRPA1 channels as LPS-induced calcium influx, membrane depolarization and neuropeptide release were absent in TRPA1 deficient mice (24). Similarly, poly(I:C), a dsRNA analogue which binds TLR3, induced inward currents and action potentials in DRG neurons resulting in itch which was absent in TLR3 deficient mice. Notably, the microRNA miRNA-let-7b, a ligand of TLR7 in mouse DRG neurons has been shown to activate nociceptors through coupling of TLR7 and TRPA1 which elicited pain (25). TLR5 has also been shown to be activated by flagellin in DRG nociceptors and addition of QX-314, a membrane impermeable analgesic, leads to TLR5-dependent blockade of neuropathic pain (26). MyD88, the common and essential intracellular signaling molecule for all TLR, has been shown to be present in the majority of DRG neurons suggesting functionality of TLRs and the ability to signal through canonical TLR signaling $(27,28)$. MyD88 activation can lead to neuronal excitation and the production of neuropeptides that can modulate the inflammatory response. Conditional depletion of MyD88 in nociceptors resulted in reduced IL-1 $\beta$-induced pain and immune cell infiltration (28). In the lung, a study detected expression of TLR2 and TLR5 in pulmonary sensory neurons using RT-PCR which might be relevant in the context of pulmonary infections (29). Thus, an expanding body of literature highlights that sensory neurons 


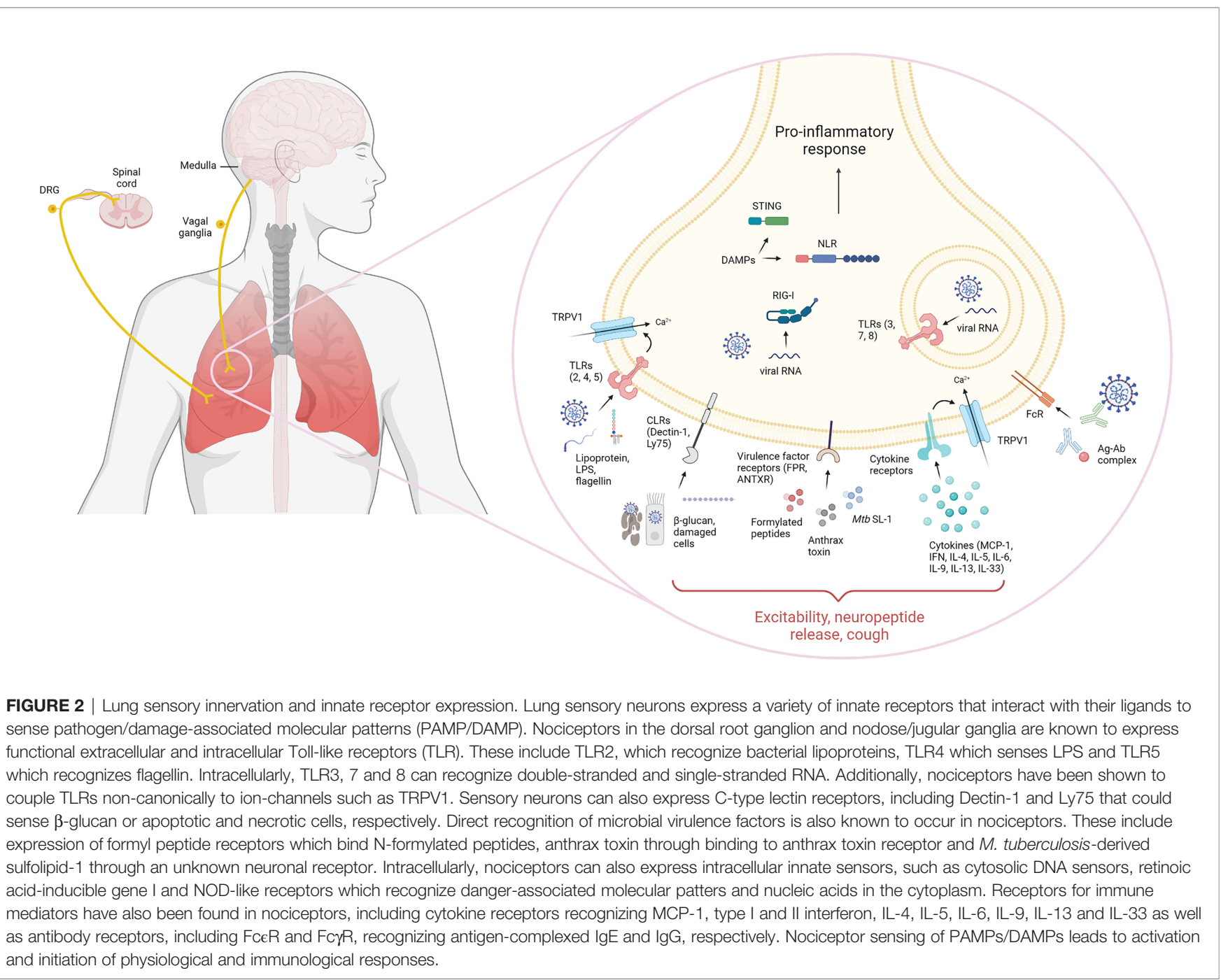

express functionally relevant detection systems of the TLR pattern recognition pathways.

\section{CLRs}

C-type lectin receptors (CLRs) are carbohydrate-binding innate receptors which bind carbohydrate moieties using conserved carbohydrate recognition domains (30). In immune cells, CLRs are important for recognition and binding to pathogens resulting in internalization, degradation, and antigen presentation (30). Some CLRs include the mannose receptor (MR), DC-associated C-type lectin (Dectin-1) and DC-specific ICAM3 grabbing non-integrin (DC-SIGN). In nociceptors, expression of CLRs remains incompletely understood. Fungal-derived $\beta$-glucan was shown to stimulate nociceptors dependent on Dectin- 1 allowing detection of the Candida albicans cell wall. Notably, Dectin-1-deficient mice were unresponsive to pain induced by Candidiasis suggesting Dectin-1-dependent recognition of fungal components (31). Furthermore, transcriptomic profiling of DRG nociceptor cells revealed high expression of Ly75 in peptidergic nociceptors (18, 32). Ly75 (also known as DEC205) has been suggested to bind apoptotic and necrotic cells (33); yet, it remains unclear iffunctional Ly75 is indeed present on nociceptors and the functional outcomes of their expression. Ly75 could promote sensing of damage to host cells upon inflammation or infection resulting in nociceptor activation and neuropeptide release. In addition, during viral infection where virus-infected cells become apoptotic, having sensors of apoptotic and necrotic cells could modulate the inflammatory response. In the lung specifically, expression of Dectin-1 or LY75 in nociceptors could be beneficial upon infectious insults that would allow lung nociceptors to sense either direct microbial structures, such as fungal $\beta$-glucan, or apoptotic and necrotic cells to steer the immune response.

\section{Virulence Factor Sensing}

Peripheral nerves can also directly recognize and become activated by microbes due to expression of receptors that can recognize microbial virulence factors. Staphylococcus aureus, a human pathogen relevant for pulmonary infections, contains virulence factors that can directly activate nociceptors. For example, DRG and trigeminal ganglia nociceptors are known to 
express G-protein coupled formyl peptide receptors Fpr1 and Fpr2 which bind $S$. aureus-derived N-formylated peptides (34). Furthermore, pore-forming toxins from $S$. aureus trigger sensory neurons through a TRPV1-dependent mechanism (35). Nociceptive neurons were also found to express the anthrax toxin receptor ANTXR2 which recognizes Bacillus anthracis derived toxins (36). Lastly, Mycobacterium tuberculosis-derived sulfolipid-1 was shown to activate nociceptive neurons and induce cough. It was suggested that the mechanism of cough was through direct activation of an unknown neuronal receptor recognizing sulfolipid-1 (37).

\section{Intracellular Innate Sensors}

Intracellular innate sensors, such as cytosolic DNA sensors, RIGI-like receptors and NOD-like receptors have been shown to be expressed in sensory neurons, however their relevance and functionality remains incompletely understood. Cytosolic DNA sensors (CDS) detect self- and pathogen-derived DNA. DNA sensing can lead to induction of type-I interferons and proinflammatory cytokines. In particular, stimulator of IFN genes (STING), an endoplasmic reticulum bound DNA sensor, has been recently shown to be highly expressed in peptidergic nociceptive neurons in the DRG $(38,39)$. Retinoic acid-inducible gene I (RIG-I)-like receptors (RLR) are nucleic acid sensors located in the cytoplasm. Nucleic acids, such as viral RNA, trigger their activation which induces the production of type I interferons and establish an anti-viral host response (40). The RLRs family include RIG-I, MDA5 and LGP2. Single-stranded RNA viruses such as coronaviruses and influenza viruses are known to be recognized by RLRs, namely RIG-I and MDA5 (41-44). Deep RNA-Seq profiling of mouse DRG neurons indicated that peptidergic nociceptor neurons exhibited high expression of $D d x 58$, the gene encoding RIG-I (18, 38). Lastly, nucleotide-binding and oligomerization (NOD)-like receptors are cytoplasmic receptors with roles in inflammasome assembly, signal transduction, transcription activation, and autophagy. scRNA-seq profiling showed expression in mouse DRG nociceptors of several NLR genes including $N$ lrx1 and $\operatorname{Nod} 1(18,32,38)$. These two nonmacromolecular scaffold-forming NLRs have a role in regulation of inflammation signaling through the activation of NF-kB, MAP kinase, and interferon regulatory factors to stimulate innate immunity (45). Yet, it remains unclear what is the functional relevance of sensory neuron expression of NLR.

\section{Cytokine Sensing}

Nociceptors have been documented to directly sense cytokines and chemokines resulting in alterations in activity and excitability. For example, CCR2, the receptor for MCP-1/CCL-2 has been found to be expressed by nociceptor neurons from DRG in models of neuropathic pain. Indeed, activation of CCR 2 by MCP-1 could sensitize nociceptors via transactivation of TRP channels (46). Additionally, sensory neurons in the mouse DRG were shown to express allergy associated type 2 cytokine receptors such as IL$4 \mathrm{R} \alpha$ and IL-13R $\alpha 1$ (47). Interestingly, sensory neuron-specific deletion of IL- $4 \mathrm{R} \alpha$ reduced chronic itch, a notable symptom of allergic diseases. Alternatively, hyperalgesia was found to be associated with pro-inflammatory pathways such as the overexpression of TNF receptors in the DRG in a model of joint pain (48). Likewise, IL-6 was shown to activate nociceptors in an antigen-induced arthritis model, resulting in neuropeptide release and joint pain (49). The pro-inflammatory cytokine IL-1 $\beta$ can be detected by IL-1R in nociceptors in the DRG leading to activation and pain allowing nociceptors to sense tissue inflammation (50). Conversely, anti-inflammatory cytokines can also have an effect in nociceptor activation. The receptor for the antiinflammatory cytokine IL-10 is known to be expressed in nociceptors in the DRG and can inhibit sensory neurons thereby alleviating pain (51-53). In the setting of viral infections, type I interferon receptors have been shown to be expressed in DRG neurons and type I IFNs can directly cause nociceptor sensitization (54). Relevant to the lung, transcript profiling of naive nodose ganglion revealed lung nociceptors expressed receptors for IL-33, IFN- $\gamma$, IL-4 and IL-9 and IL-5. Notably, innate lymphoid cell 2 (ILC2)-derived IL-5 directly activates sensory neurons driving allergic airway inflammation (55). Thus, during inflammation, pro-inflammatory cytokines can directly activate sensory neurons that could contribute to the amplification of the inflammatory response and effector functions of immune cells through the release of neuropeptides.

\section{Antibody Receptors}

Antibodies can be recognized by Fc receptors present in immune cells to carry out antibody effector functions. Recent studies have elucidated that Fc-gamma receptors, recognizing IgG antibodies, are present in a subpopulation of DRG nociceptors which are activated by immune complexes and result in increased neuronal excitability (56). Interestingly, in the context of allergic airway inflammation, the high affinity $\mathrm{Fc}$-epsilon receptor $(\mathrm{Fc \in R} 1)$, recognizing $\operatorname{IgE}$ antibodies that mediate allergic responses, is expressed in the jugular/nodose ganglion. Allergen-complexed IgE resulted in depolarization, action potential firing, calcium influx and neuropeptide release which initiated and amplified allergic airway inflammation through the release of substance $\mathrm{P}$, promoting a Th2 phenotype in the airways (57). In response, substance $\mathrm{P}$ also induces formation of antibody producing cells as well as the release of IgE (58). The role of antibody-antigen complexes in infectious diseases, such as respiratory viral infections and the expression of Fc receptors in lung nociceptors remains elusive. However, it could be possible that antibody-virus complexes may be recognized by lung nociceptors and might trigger neuronal excitation and neuropeptide release to modulate the immune response.

Overall, despite the characterization of innate receptors function in nociceptors, few studies have characterized their relevance in the setting of lung diseases. The anatomical distribution of sensory neurons throughout the respiratory tract allows these cells to rapidly detect aspirated threats and initiate physiological as well as immunological responses.

\section{NOCICEPTOR-INDUCED RESPONSES IN THE LUNGS}

As discussed earlier, the upper and lower respiratory tracts are densely innervated with sensory, sympathetic, and 
parasympathetic fibers that work together to maintain a broad range of homeostatic functions. One such important function is the initiation of reflex arcs that remove threats such as pathogens and/or limit exposure to other noxious stimuli present in the air (59). A key example is the cough reflex arc which clears the airways of foreign objects and secretions. Interestingly, aberrant lung nociceptor function has been implicated in a variety of respiratory diseases such as chronic cough, asthma, and airway hyperreactivity (10).

Triggering tachypnea, bronchoconstriction, and increased mucus secretions, C-fibers respond to activators of TRPV1 and TRPA1 channels (capsaicin and allyl isothiocyanate, respectively), inflammatory mediators (e.g. bradykinin, prostaglandin E2), and environmental irritants (e.g. ozone, nicotine) (60). Conversely, A-fibers lack the prototypical nociceptive ion channels such as TRPV1 and TRPA1 (61). Instead, they are activated by mechanical cues such as sustained lung inflation and aspiration associated stimulus (i.e., punctate mechanical stimuli and $\mathrm{H}^{+}$). Upon activation, a shared physiological response of both $\mathrm{A}$ - and C-fibers is the cough reflex (10).

Following their stimulation, A- and C-fibers send impulses via the afferent pathway to the vagus nerve which relays the signal to the medulla oblongata in the brainstem (62). The central pathway (referred to as the 'cough center') of the medulla then produces yet another impulse which is sent through various efferent pathways (i.e. vagus, phrenic, and spinal motor nerves) to recruit the diaphragm, abdominal wall and expiratory muscles for cough production. Subsequently, the events of coughing can be divided into 3 stages: inspiratory, compression, and expiratory phase (10). During the inspiratory phase, brief inspiration ensures adequate volumes of air are present for cough production. Next, intrapulmonary pressures massively increase as the muscles of the chest wall, diaphragm, and abdominal wall contract - resulting in expiration against a closed glottis. Lastly, the expiratory phase is characterized by opening of the glottis, high expiratory velocities, and expulsion of mucus and/or foreign objects from the airways (62).

To the best of our knowledge, there are few articles discussing innate sensing of pathogens via nociceptors and the cough reflex. For example, Mycobacterium tuberculosis initiates cough via SL1 (37). Furthermore, Bordetella pertussis, which is the causative agent of whooping cough is sensed by TLR4 found on resident and infiltrating leukocytes (63). This results in the production of strong proinflammatory mediators such as IFN- $\gamma$, nitric oxide (NO), and TNF- $\alpha$. Subsequently, other studies have shown, albeit in different animal models, that application of TNF- $\alpha$ reduces neuronal activation thresholds and evokes A- and Cfiber depolarization $(64,65)$.

Another feature of sensory neuron function is the modulation of the immune response in mucosal tissues. This neuroimmune crosstalk is necessary for a proper coordination of the immune response which will efficiently combat pathogen spread, without an overwhelming inflammation, maintaining homeostasis and tissue integrity. Neuroimmunity is well described in the gut and skin, but poorly explored in the lungs. Hence, we highlight comparisons with neuroimmune interactions in the skin, where applicable.

Interestingly, neurogenic inflammation has been shown to initiate pulmonary pathological processes, such as asthma and rhinitis. Depletion or suppression of sensory neurons results in reduced allergic airway inflammation and bronchial hypersensitivity. Mechanistically, IL-5-activated sensory neurons release neuropeptides, such as VIP and NMU, which induce ILCs to produce type 2 cytokines, such as IL-5 and IL-13, contributing to the allergic response $(55,66)$. On the other hand, CGRP leads to regulation of ILC2-derived type 2 cytokines, demonstrating that distinct release of neuropeptides drives different outcomes in ILC2-mediated airway hypersensitivity responses (67). In the setting of allergic responses in the skin, upon cutaneous allergen-exposure sensory neurons are activated and release Substance $P$ which stimulates dendritic cell migration to the lymph node and promotes Th2 differentiation and the initiation of an allergic response (68). Similarly, in a model of atopic dermatitis, allergen activated TRPV1+ nociceptors drove the development of allergic skin inflammation through production of Substance $\mathrm{P}$ which triggered mast cell degranulation (69). On the other hand, sensory neurons can also restrain inflammation and support healing by promoting a reparative phenotype in macrophages in a sunburn-like mouse model. Release of the neuropeptide TAFA4 promoted macrophage production of IL-10 which reduced skin inflammation, promoted tissue regeneration, and prevented fibrosis (70).

Regarding host defense, lung sensory neurons can regulate or activate the inflammatory response. CGRP prevents Nippostrongylus brasiliensis expulsion through the regulation of IL-33 and NMU-activated ILC2 (71). No reports have explored the role of fungal infection in the lungs with regards to neuroimmune crosstalk. Nevertheless, within the skin, Candida albicans can trigger sensory neurons via Dectin-1, which in response, release CGRP. This neuropeptide induces the release of IL-23 by CD301b+ dendritic cells, resulting in Th17 and $\gamma \delta \mathrm{T}$ cells mediated response, thus augmenting host defense $(72,73)$. During lung pneumonia induced by severe $S$. aureus infection, activated TRPV1+ neurons release CGRP in response to the bacterial infection, which in counterpart, regulate neutrophil and $\gamma \delta \mathrm{T}$ cell function. As a result, host defense is compromised, leading to bacterial proliferation and systemic dissemination resulting in lethal infection. CGRP blocking prevents neutrophil regulation, thus augmenting host defense (74). Similarly, in the context of skin infection with S. pyogenes, nociceptors suppress immune responses by releasing CGRP which inhibits neutrophil recruitment and subsequent killing of the bacteria. Botulinum neurotoxin A and CGRP blocking prevented suppression of neutrophil responses thus promoting host defense against S. pyogenes infection (75). On the other hand, Substance P and Gastrin-releasing peptide (GRP) release by sensory neurons can induce neutrophil chemotaxis and formation of neutrophil-neuron clusters (76). In the skin, optogenetic activation of sensory neurons in TRPV1-Ai32 mice elicited a type 17 immune response that induced significant 
neutrophil and $\mathrm{T}$ cell recruitment via release of CGRP. This response was protective in the context $C$. albicans and $S$. aureus infection and extended beyond the site of stimulation via a nerve-reflex arc (72). These pieces of evidence support the concept that neuromodulation of neutrophils depends on which neuropeptides are released as well as the inflammatory context. In response, neutrophils produce hypernociceptive factors, such as PGE2, ROS and sympathetic amines, increasing sensory neuron activation threshold (77).

In the context of virus infection, few studies have explored whether viruses can trigger nociceptors and the immunological consequences. During herpes simplex virus 1 infection, sensory neurons regulate neutrophil infiltration into the skin, concomitantly with the induction of a CD8 T cell-mediated antiviral response which limited the severity of tissue damage and restoration of skin homeostasis (78). Within the lungs, type I Interferon directly activates nociceptors, leading to neuronal depolarization (79). Recently, the world has experienced the consequences of the SARS-CoV-2 pandemic in which millions of people have succumbed to this infection. Furthermore, recent evidence has suggested that human sensory neurons express the receptors ACE2 and SCARF on their surface, which are used by SARS-CoV-2 for cell entry (80). Thus, it is plausible to suggest that sensory neurons can be infected and might explain some of the respiratory symptoms observed in COVID-19 patients, such as cough and loss of smell. Whether SARS-CoV-2 can be detected by sensory neurons through innate receptors and the physiological as well as the immunological consequences are still unexplored.

\section{COVID-19 AND NOCICEPTORS}

Since the beginning of the COVID-19 pandemic, SARS-CoV-2 infection has been described to cause airway damage, such as loss of multiciliated cells and alveolar disruption (81). Much of the damage in the lungs can also be due to overwhelming inflammation as well as reduced antiviral response, which leads to tissue injury and organ dysfunction. Single cell analyses reported impaired type I IFN response and increased expression of pro-inflammatory cytokines and chemokines in the lungs of COVID-19 patients (82-84). Furthermore, neuropathological features have been found in autopsies of COVID-19 patients in which an inflammatory infiltration as well as activated immune cells were found in specific regions of the central nervous system (85). Therefore, this suggests that neurological consequences might be mediated by neuroinflammation. Whether this neuroimmunopathological mechanisms occurs in the lungs and their consequences remains unanswered. The developments of models, such as hACE2 mice model (86) as well as organoids (87), has allowed a better understanding of the mechanisms through which SARSCoV-2 infects and mediates COVID-19 pathology, including in the airways innervation. Furthermore, a ligand-receptor interactome analyzed bulk RNA-seq data from COVID-19 patients and human DRG gene expression. They found increased expression of pro-inflammatory chemokines (e.g. CCLs and CXCLs) within COVID-19 bronchoalveolar lavage fluid (BALF) as well as expression of their receptors by human DRGs, suggesting a connection between inflammation and sensory neurons activation (88). In the next paragraphs, we will cover some of the findings and discuss possible roles for sensory neurons in COVID-19. A representation of the relation between COVID-19 and nociceptors is represented by Figure 3.

To better understand the current pandemic, it is essential to evaluate the previous knowledge gained during the initial SARS pandemic. Earlier work with SARS-CoV demonstrated the neurotropic potential of SARS coronaviruses which correlated with neuronal and psychological abnormalities in SARS patients (89). SARS-CoV was shown to cause neuronal death in hACE2-transgenic mice and SARS-CoV patients had viral RNA in their cerebrospinal fluid (90-93). In vitro, human and rat neuron cell lines were also susceptible to infection by SARS-CoV (94). It was proposed SARS-CoV could gain entry into the central nervous system by infecting olfactory nerves and subsequently disseminating (91). Notably, viral E protein was shown to be important for neurotropism (95). E proteindeficient SARS-CoV, lacking E protein ion channel activity was less virulent and caused less inflammation in animal models (96, 97). The absence of $\mathrm{E}$ protein can affect viral particle release from infected cells and result in decreased viral loads and inflammation. However, the ion channel activity of the $\mathrm{E}$ protein could also potentially directly affect the neuronal membrane, resulting in neuron death and neurogenic inflammation, which would not be present during infection with E protein-deficient SARS-CoV. Hence, the combination of direct neuron infection and the effects of viral proteins of neuronal cells, provide some hints into the neurological symptoms and potentially places neurons as drivers of inflammation during infection with coronaviruses.

A common feature manifested by COVID-19 patients is the loss of taste and smell (98). Similar to SARS-CoV, it suggests that olfactory sensory neurons can be affected by SARS-CoV-2 infection, resulting in loss of function and/or neuronal death. Indeed, in olfactory mucosa brush cytological sampling from COVID-19 patients with loss of smell, SARS-CoV-2 was detected in sensory neurons as well as non-neuronal sensory epithelial cells. Staining of cleaved caspase-3 in these cells suggests cell death induction (99). Curiously, single-cell analyses have shown that olfactory sensory neurons do not express ACE2 and TMPRSS2 (100); nevertheless, Neuropilin-1, a receptor for furin-cleaved substrate, can facilitate SARS-CoV-2 infection within olfactory epithelium (101). Furthermore,SARS-CoV-2derived $\mathrm{E}$ protein can form a $\mathrm{pH}$ sensitive ion channel at the membrane of several cell lines, which causes their death and an overwhelming secretion of cytokines and chemokines (102). As mentioned before, sensory neuron activation through TRP channels induces ion influx and neuron firing, resulting in release of neuropeptides. There is no evidence of direct olfactory sensory neuron activation by SARS-CoV-2; nevertheless, it is plausible that SARS-CoV-2-derived E protein could form a pore in the membrane of sensory neurons, resulting 


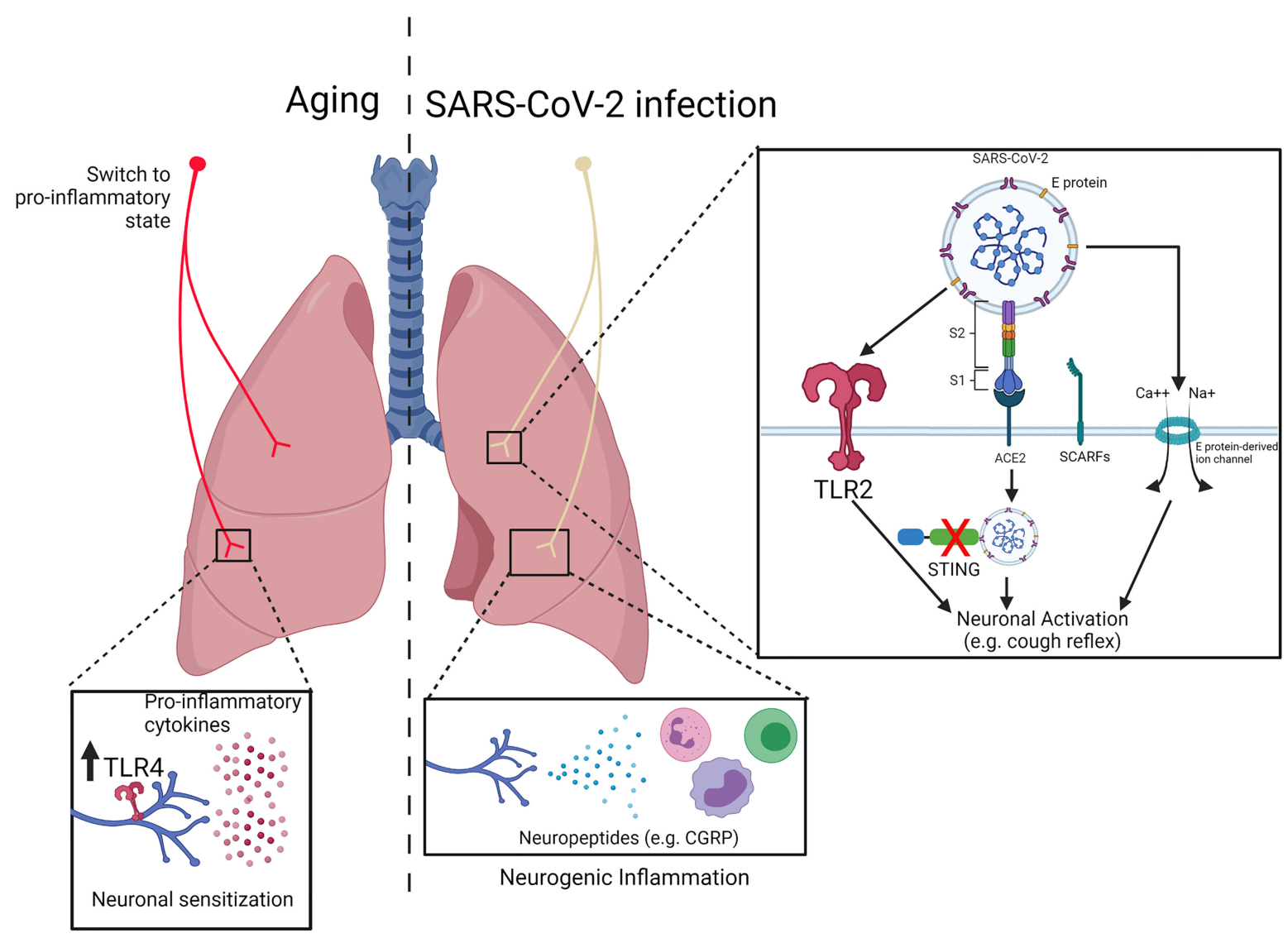

FIGURE 3 | Impact of innate receptor expression in nociceptors during aging and COVID19. (Left) During aging, nociceptors switch from an anti-inflammatory to a pro-inflammatory state. Inflammaging results in an increased production of pro-inflammatory cytokines (e.g. TNF- $\alpha$, IL-1 $\beta$, IL-6) which might contribute to neuronal sensitization. Nevertheless, increase in the expression of innate receptors (e.g. TLR4) might contribute sensory neurons activation. (Right) SARS-CoV-2 has been described to trigger TLR2 as well as induce cell activation/death via E protein-mediated ion channel formation, which could lead to neuronal activation. Furthermore, expression of the receptors ACE2 and SCARFs by human dorsal root ganglia suggest that nociceptors can be a target of SARS-CoV-2 infection. Within the cell, the virus can block STING-mediated signaling, resulting in neuronal activation. Adapted from "Mechanism of SARS-CoV-2 Viral Entry", by BioRender.com (2020).

Retrieved from https://app.biorender.com/biorender-templates.

in cellular death and exaggerated neuropeptides release, which would explain the symptoms mentioned above.

Some COVID-19 patients manifest persistent symptoms even months after the initial insults. These symptoms, known as postacute COVID-19 syndrome, include recurrent cough which indicates that sensory neurons can be chronically activated $(103,104)$. Although this reflex contributes to viral spread during acute infection through the dispersion of viruscontaining droplets from the airways, it is less clear how and why chronic cough develops once the virus is eliminated. Blocking cough in the acute setting is a potential mechanism to prevent viral spread and this may result in alleviating chronic symptoms (105). Recently, the innate receptor TLR2 was found to recognize SARS-CoV-2 E protein, resulting in an inflammatory response (106). Lung nociceptors express TLR2 (18), which suggests that they could also be activated by SARS-CoV-2 via this innate receptor and trigger neuronal activation. Additionally, COVID-19 patients can have an overwhelming production of several cytokines. A large study correlated serum levels of TNF- $\alpha$ and IL- 6 with disease severity and death of COVID-19 patients (107). Despite the absence of evidence, it is possible that these cytokines could directly activate lung sensory neurons and trigger cough reflex as well as contribute to neurogenic inflammation. Even though production of antibodies is one of the most effective immunoprotective mechanisms of our body, recent evidence has demonstrated a deleterious role, such as the generation of autoantibodies against type I IFN, which prevents viral clearance (108). Furthermore, in the context of airway hypersensitivity, increased levels of $\operatorname{IgE}$ are correlated with overwhelming pulmonary mast cell degranulation and histamines release, resulting in bronchoconstriction and blockage of the respiratory tract (109). Lung nociceptors express functional FceR1, which triggers neuronal activation (57). Thus, production of IgE during SARS-CoV-2 infection could be contributing for sensory neurons activation along the 
respiratory tract and initiate cough. Omalizumab, an IgE blocker currently approved for the treatment of asthma, nasal polyps and urticaria, has been suggested as a promising COVID-19 treatment to prevent excessive airway hypersensitivity response. If IgE is proven to induce sensory neuron-mediated neurogenic inflammation, this treatment could be a promising candidate for COVID-19 treatment (110).

Human dorsal root ganglia express ACE2 and SCARFs receptors, which are used by SARS-CoV-2 for cell entry (80). Within the sensory neuron, SARS-CoV-2 might interact with intracellular innate receptors, leading to activation or regulation. Future studies will clarify if this recognition occurs. Nevertheless, as mentioned before, nociceptors express STING, which its activation results in regulation of nociceptive sensation via IFN-signaling (39). Importantly, SARS-CoV-2-derived ORF3a has been found to block STING activation (111). It is possible that blockage of STING signaling by SARS-CoV-2 would not only impair anti-viral immune response, but would also increase nociceptor sensitization, thus leading to cough reflex and viral spread. Indeed, pharmacological activation of STING using small-molecule agonists prevents SARS-CoV-2 infection via IFN-signaling (112). If proven that SARS-CoV-2 induces nociceptor sensitization via STING blockage, the treatment with agonists could potentially prevent nociceptor activation and the cough response.

Post-acute COVID-19 syndrome affects both the respiratory and nervous systems (104). Increased levels of neuro-axonal damage marker in the peripheral blood of COVID-19 patients suggests directly or indirectly injury to neurons $(113,114)$. Whether lung sensory neurons could be chronically damaged by SARS-CoV-2 infection is poorly described. Therapeutic approaches targeting TRPV1 sensory neurons using resiniferatoxin, a potent TRPV1 agonist, have been suggested for use in patients with severe COVID-19 (115). SARS-CoV-2 has neurotropic potential suggesting nociceptors could be a reservoir for the virus and drive symptoms. Hence, ablation of TRPV1+ nociceptors could be beneficial as a therapeutic strategy. Depletion of nociceptors that could be chronically activated and potentially drive inflammation, could modulate the immune response, and help improve outcomes. Moreover, blocking CGRP for example, by means of anti-CGRP antibodies used for migraine treatment, could prevent the excess neuropeptide release that might contribute to the hyperinflammatory response in patients with severe COVID19 (116). TRPV1 neuron depletion and CGRP antagonism has been proven to be favorable in animal models of bacterial pneumonia as TRPV1+ sensory neurons suppressed protective immune responses through CGRP release (74). However, the effectiveness of these strategies in the context of respiratory viral infections remains undefined. It is also possible that in the setting of COVID-19 hyperinflammation, the absence of immune modulation through neuropeptide release by sensory neurons could have a detrimental effect. Levels of CGRP were found to be decreased in COVID-19 patients. Despite the absence of correlation with disease severity, these findings suggest that neuroinflammation might influence COVID-19 outcome (117).
Yet, TRPV1+ nociceptors could also become more proinflammatory with age, in which case it would make sense to block afferent signaling from TRPV1 sensory neurons in elderly COVID-19 patients (118).

\section{AGING, NOCICEPTION, AND IMPLICATIONS FOR IMMUNE FUNCTION}

Similar to many diseases, lung infections including bacterial pneumonia, and COVID-19, older patients have increased susceptibility and worse clinical outcomes. Although data is emerging, it remains unclear if and how an aged neuronal sensory system contributes to clinical differences in diseases that target the lung and breathing. Aging is a natural and continuous part of everyday life. Even barring pathological processes such as degenerative diseases, cancers, and/or lifestyle-related illnesses (e.g. high blood pressure, diabetes etc.), aging brings about significant changes to physiological functions. Such changes have been well-characterized elsewhere, from age-related fertility decline to decreased renal and hepatic function, no organ system is left untouched (119121). Given our current knowledge of associations between the immune and nervous system, innate sensing by nociceptors likely plays a major part in facilitating bidirectional signaling involved in pain sensation and inflammation. What is less clear is the mechanism by which neuroimmune interactions influence pulmonary host defense as we age. A representation of the possible role of aging in nociceptors is represented by Figure 3.

Briefly, it has been known for more than three decades that aging brings about widespread changes to the nervous system (122). Neurocognitive declines seen in dementia/Alzheimer's and a host of other maladies are increasingly becoming linked with age-related demyelination, neuronal density and synapse structure changes $(123,124)$, as well as alterations in neuropeptide release (125). These also coincide with changes to pain perception and nociceptive pathways $(126,127)$. Similarly, with regards to lung function, development ends at around 20-25 years of age (128). Starting in the third and fourth decade of life, respiratory function gradually begins to decline because of anatomical changes in the lung parenchyma and weakening respiratory muscles (129). Such changes can be readily measured and tracked with lung function tests and typically manifest in symptoms such as shortness of breath (especially with exertion), chest pain, and chronic cough (115). Additionally, older individuals tend to be at a higher risk of developing pneumonias and other respiratory infections (130).

A key factor for this susceptibility is age-related immune dysregulation. More specifically, a systemic increase in baseline inflammation stemming from innate immune system activation despite the absence of any immunological threats (130). Indeed, the immune system is equally vulnerable to deteriorations with age - a phenomenon termed as 'inflammaging'. Inflammaging's prevailing phenotype is one of elevated proinflammatory cytokines (particularly IL-1 $\beta$, IL-6, and TNF- $\alpha$ ) and aberrant leukocyte trafficking (131). For instance, in murine models, neutrophils 
from aged mice adhere to and breach the vascular endothelium at a higher frequency than those of young mice. Re-entering systemic circulation, these neutrophils have the potential for eliciting peripheral organ injury as evidenced by their contribution to enhanced vascular leakage within the lung (132). Peculiarly, despite this heightened immunological activation, inflammaging is closely associated with a dampened ability to respond to pathogenic threats or tissue injury (termed immunosenescence) (133).

The impact of aging in innate receptors expression is controversial. Expression of TLR1, 2, 3, 4, 5, and 11 and their downstream signaling pathway molecules MyD88 and PhosphoIRF-3 were reported to be significantly elevated in aged renal tissues sourced from rats (134). Meanwhile, other studies have reported opposite observations in which expression of TLR1 and TLR4 decreased in human monocytes with aging (135). Similar trends have been observed in other immune cell types such as macrophages and plasmacytoid dendritic cells which show significantly decreased TLR1-TLR9 expression in aged mice and reduced TLR7 or TLR9 in older humans, respectively (136). These discordant findings have made it difficult to ascertain the precise effect(s) of aging on innate receptors over the lifespan.

While it is not entirely clear which mechanisms influences the immune system as we age, recent findings pertaining to TRPV1 nociceptor function (particularly in the context of aging) have provided intriguing clues. In addition to their canonical role as sensors of noxious stimuli, TRPV1 neurons have been shown to possess important immunoregulatory roles. As mentioned before, lung nociceptors suppress neutrophil recruitment and surveillance during infection via the release of neuropeptides, such as CGRP (74). Similar findings have been reported in the context of systemic inflammatory response syndrome (SIRS); whereby TRPV1 nociceptors plays an immunosuppressive role by inhibiting production of TNF- $\alpha$ (118). Thus, the antiinflammatory phenotype of TRPV1 nociceptors appears to be conserved across various illnesses.

Interestingly, the anti-inflammatory actions of TRPV1 may reverse with aging. Wanner et al. found that pharmacological or genetic ablation of TRPV1 in young mice resulted in increased mortality during aseptic SIRS. Whereas the opposite occurred for aged mice - with TRPV1 antagonism in aged mice resulting in greater survival during aseptic sepsis (118). They also noted decreased serum TNF- $\alpha$ in TRPV1 knockout mice when compared with age-matched wildtype littermates; suggesting that TRPV1 inhibition of TNF- $\alpha$ production may also be reversed with aging. One possible explanation for why this may occur is that neurons that previously possessed anti-inflammatory properties begin to transition into a more proinflammatory state through aging. Thus, when their effects are blocked in older mice experiencing sepsis, excessive neurogenic inflammation is decreased, preventing death (118). Indeed, levels of neuropeptides, such as CGRP and VIP, are dysregulated in aged mice, which impacts physiological functions, like metabolic homeostasis $(125,137)$. Nevertheless, the mechanisms behind aginginduced nociceptors modulation and the influence in the immune system are poorly described.
Chronic cough is more prevalent in the elderly population, potentially implicating lung sensory neurons sensitization as we age (138). This could be explained by the increased levels of proinflammatory cytokines which could chronically activate lung nociceptors and trigger cough reflex. To the best of our knowledge, there is no evidence showing whether sensory neurons can upregulate innate receptors expression as we age neither the impact on the immune system. Nevertheless, upregulation of TLR4 expression in hippocampal neuron of aged mice leads to higher response upon LPS injection, resulting in neuronal death (139). It suggests that neurons can upregulate innate receptors as we age. Future studies will elucidate whether aging increases expression of innate receptors in nociceptors, potentially contributing to neurogenic inflammation in elderly individuals.

It is well-established that individuals with underlying medical conditions are at a higher risk of complications and/or death from COVID-19. Many of these underlying conditions such as COPD and chronic kidney disease are becoming increasingly linked with defective neuroimmune interactions $(140,141)$. However, what is less certain are the underlying age-related mechanisms driving differences in COVID-19 disease severity. Numerous hypotheses for the link between COVID-19 lung injury and aging have been posited. For example, greater pre-existing immunity to commonly circulating human coronaviruses in adults and geriatric patients may facilitate COVID-19 cell entry and viral replication via nonneutralizing antibodies (142). Similarly, age-related increases in expression and affinity of ACE2 receptors may be another driving factor in severe COVID-19 (143). A potential neuroimmune explanation may be that if neurons are indeed a target for the virus, it is then plausible that in the elderly, the neurogenic inflammation that results from COVID-19 infection combined with immunosenescence and inflammaging guides the severe natural history of disease. Furthermore, higher levels of neuron damage markers are found in the blood of elderly COVID-19 patients, suggesting that neuronal infection and damage might contribute to increased susceptibility (113). Therefore, we suggest that therapeutically blocking neuroimmune mediated inflammation could lead to similarly reduced mortality and better clinical outcomes in COVID-19 patients, especially in elderly individuals.

\section{CONCLUDING REMARKS}

The neuroimmune crosstalk in the lungs is still poorly described. Notably, the mechanisms through which lung sensory neurons are activated during pulmonary diseases and the relevance of innate receptors remain even less well defined. Here, we review recent evidence which highlights the importance of innate receptors in lung nociceptors with regards to their expression as well as the physiological and immunological consequences of their activation via these receptors. Furthermore, we also describe the possible involvement of nociceptors during SARSCoV-2 infection as well as their functional changes and activation during aging. Whether the increased susceptibility of 
elderly patients to SARS-CoV-2 infection is mediated by lung nociceptors remains an unanswered question. Nevertheless, recent evidence is contributing to our understanding of the mechanisms behind pulmonary neuroimmune crosstalk, which will open the possibility for promising therapeutic targets for lung diseases.

\section{AUTHOR CONTRIBUTIONS}

All the authors contributed with intellectual discussion, figures preparation, and manuscript writing.

\section{REFERENCES}

1. De Troyer A, Boriek AM. Mechanics of the Respiratory Muscles. In: Comprehensive Physiology. Wiley (2011). p. 1273-300. doi: 10.1002/ cphy.c100009

2. Fröhlich E, Mercuri A, Wu S, Salar-Behzadi S. Measurements of Deposition, Lung Surface Area and Lung Fluid for Simulation of Inhaled Compounds. Front Pharmacol (2016) 7:181. doi: 10.3389/ fphar.2016.00181

3. Knudsen L, Ochs M. The Micromechanics of Lung Alveoli: Structure and Function of Surfactant and Tissue Components. Histochem Cell Biol (2018) 150(6):661-76. doi: 10.1007/s00418-018-1747-9

4. Cohen SB, Gern BH, Delahaye JL, Adams KN, Plumlee CR, Winkler JK, et al. Alveolar Macrophages Provide an Early Mycobacterium Tuberculosis Niche and Initiate Dissemination. Cell Host Microbe (2018) 24(3):439-46.e4. doi: 10.1016/j.chom.2018.08.001

5. Neupane AS, Willson M, Chojnacki AK, Vargas E, Silva Castanheira F, Morehouse C, et al. Patrolling Alveolar Macrophages Conceal Bacteria From the Immune System to Maintain Homeostasis. Cell (2020) 183(1):11025.e11. doi: 10.1016/j.cell.2020.08.020

6. Granton E, Kim JH, Podstawka J, Yipp BG. The Lung Microvasculature Is a Functional Immune Niche. Trends Immunol (2018) 39(11):890-9. doi: 10.1016/j.it.2018.09.002

7. van Manen MJG, Birring SS, Vancheri C, Cottin V, Renzoni EA, Russell AM, et al. Cough in Idiopathic Pulmonary Fibrosis. Eur Respir Rev (2016) 25 (141):278-86. doi: 10.1183/16000617.0090-2015

8. Chang RB, Strochlic DE, Williams EK, Umans BD, Liberles SD. Vagal Sensory Neuron Subtypes That Differentially Control Breathing. Cell (2015) 161(3):622-33. doi: 10.1016/j.cell.2015.03.022

9. Kubin L, Alheid GF, Zuperku EJ, Mccrimmon DR, Alheid GF, Zuperku EJ, et al. Reflexes From the Lungs and Airways Central Pathways of Pulmonary and Lower Airway Vagal Afferents. J App Physiol (2021) 136:618-27. doi: 10.1152/japplphysiol.00252.2006

10. Mazzone SB, Undem BJ. Vagal Afferent Innervation of the Airways in Health and Disease. Physiol Rev (2016) 96(3):975-1024. doi: 10.1152/ physrev.00039.2015

11. Kupari J, Häring M, Agirre E, Castelo-Branco G, Ernfors P. An Atlas of Vagal Sensory Neurons and Their Molecular Specialization. Cell Rep (2019) 27(8):2508-23.e4. doi: 10.1016/j.celrep.2019.04.096

12. Hennel M, Harsanyiova J, Ru F, Zatko T, Brozmanova M, Trancikova A, et al. Structure of Vagal Afferent Nerve Terminal Fibers in the Mouse Trachea. Respir Physiol Neurobiol (2018) 249:35-46. doi: 10.1016/ j.resp.2018.01.001

13. Undem BJ. The Role of Vagal Afferent Nerves in Chronic Obstructive Pulmonary Disease. Proc Am Thorac Soc (2005) 2(4):355-60. doi: 10.1513/ pats.200504-033SR

14. Sousa-Valente J, Andreou AP, Urban L, Nagy I. Transient Receptor Potential Ion Channels in Primary Sensory Neurons as Targets for Novel Analgesics. Br J Pharmacol (2014) 171(10):2508-27. doi: 10.1111/bph.12532

15. Long L, Yao H, Tian J, Luo W, Yu X, Yi F, et al. Heterogeneity of Cough Hypersensitivity Mediated by TRPV1 and TRPA1 in Patients With Chronic

\section{FUNDING}

This work was supported with an operating grant from the Canadian Institutes of Health Research (RS-342013), a Beverley Phillips Graduate Scholarship (to $\mathrm{CH}$ ) and a tier II Canada Research Chair in Pulmonary Immunology, Inflammation and Host Defense (to BY).

\section{ACKNOWLEDGMENTS}

The figures were created using BioRender.com.

Refractory Cough. Respir Res (2019) 20(1):112. doi: 10.1186/s12931-0191077-z

16. Kawasaki T, Kawai T. Toll-Like Receptor Signaling Pathways. Front Immunol (2014) 5:461. doi: 10.3389/fimmu.2014.00461

17. Akira S, Takeda K. Toll-Like Receptor Signalling. Nat Rev Immunol (2004) 4 (7):499-511. doi: 10.1038/nri1391

18. Donnelly CR, Chen O, Ji R-R. How Do Sensory Neurons Sense Danger Signals? Trends Neurosci (2020) 43(10):822-38. doi: 10.1016/j.tins. 2020.07.008

19. Li Y, Adamek P, Zhang H, Tatsui CE, Rhines LD, Mrozkova P, et al. The Cancer Chemotherapeutic Paclitaxel Increases Human and Rodent Sensory Neuron Responses to TRPV1 by Activation of TLR4. J Neurosci (2015) 35 (39):13487-500. doi: 10.1523/JNEUROSCI.1956-15.2015

20. Diogenes A, Ferraz CCR, Akopian AN, Henry MA, Hargreaves KM. LPS Sensitizes TRPV1 via Activation of TLR4 in Trigeminal Sensory Neurons. J Dent Res (2011) 90(6):759-64. doi: 10.1177/0022034511400225

21. Jia L, Lee S, Tierney JA, Elmquist JK, Burton MD, Gautron L. TLR4 Signaling Selectively and Directly Promotes CGRP Release From Vagal Afferents in the Mouse. eNeuro (2021) 8(1):1-16. doi: 10.1523/ENEURO.0254-20.2020

22. Rudick CN, Billips BK, Pavlov VI, Yaggie RE, Schaeffer AJ, Klumpp DJ. Host-Pathogen Interactions Mediating Pain of Urinary Tract Infection. J Infect Dis (2010) 201(8):1240-9. doi: 10.1086/651275

23. Szabo-Pardi TA, Barron LR, Lenert ME, Burton MD. Sensory Neuron TLR4 Mediates the Development of Nerve-Injury Induced Mechanical Hypersensitivity in Female Mice. Brain Behav Immun (2021) 97:42-60. doi: 10.1016/j.bbi.2021.06.011

24. Meseguer V, Alpizar YA, Luis E, Tajada S, Denlinger B, Fajardo O, et al. TRPA1 Channels Mediate Acute Neurogenic Inflammation and Pain Produced by Bacterial Endotoxins. Nat Commun (2014) 5:3125. doi: $10.1038 /$ ncomms4125

25. Park C-K, Xu Z-Z, Berta T, Han Q, Chen G, Liu X-J, et al. Extracellular MicroRNAs Activate Nociceptor Neurons to Elicit Pain via TLR7 and TRPA1. Neuron (2014) 82(1):47-54. doi: 10.1016/j.neuron.2014.02.011

26. Xu Z-Z, Kim YH, Bang S, Zhang Y, Berta T, Wang F, et al. Inhibition of Mechanical Allodynia in Neuropathic Pain by TLR5-Mediated A-Fiber Blockade. Nat Med (2015) 21(11):1326-31. doi: 10.1038/nm.3978

27. Liu X-J, Zhang Y, Liu T, Xu Z-Z, Park C-K, Berta T, et al. Nociceptive Neurons Regulate Innate and Adaptive Immunity and Neuropathic Pain Through MyD88 Adapter. Cell Res (2014) 24(11):1374-7. doi: 10.1038/ cr.2014.106

28. Liu X-J, Liu T, Chen G, Wang B, Yu X-L, Yin C, et al. TLR Signaling Adaptor Protein MyD88 in Primary Sensory Neurons Contributes to Persistent Inflammatory and Neuropathic Pain and Neuroinflammation. Sci Rep (2016) 6(1):28188. doi: 10.1038/srep28188

29. Jung WJ, Lee SY, Choi SI, Kim B-K, Lee EJ, In KH, et al. Toll-Like Receptor Expression in Pulmonary Sensory Neurons in the Bleomycin-Induced Fibrosis Model. PloS One (2018) 13(3):e0193117. doi: 10.1371/journal. pone.0193117

30. Geijtenbeek TBH, Gringhuis SI. Signalling Through C-Type Lectin Receptors: Shaping Immune Responses. Nat Rev Immunol (2009) 9 (7):465-79. doi: $10.1038 /$ nri2569 
31. Maruyama K, Takayama Y, Sugisawa E, Yamanoi Y, Yokawa T, Kondo T, et al. The ATP Transporter VNUT Mediates Induction of Dectin-1-Triggered Candida Nociception. iScience (2018) 6:306-18. doi: 10.1016/j.isci.2018.08.007

32. Chiu IM, Barrett LB, Williams EK, Strochlic DE, Lee S, Weyer AD, et al. Transcriptional Profiling at Whole Population and Single Cell Levels Reveals Somatosensory Neuron Molecular Diversity. Elife (2014) 3:e04660. doi: 10.7554/eLife.04660

33. Shrimpton RE, Butler M, Morel A-S, Eren E, Hue SS, Ritter MA. CD205 (DEC-205): A Recognition Receptor for Apoptotic and Necrotic Self. Mol Immunol (2009) 46(6):1229-39. doi: 10.1016/j.molimm.2008.11.016

34. Chiu IM, Heesters BA, Ghasemlou N, Von Hehn CA, Zhao F, Tran J, et al. Bacteria Activate Sensory Neurons That Modulate Pain and Inflammation. Nature (2013) 501(7465):52-7. doi: 10.1038/nature12479

35. Blake KJ, Baral P, Voisin T, Lubkin A, Pinho-Ribeiro FA, Adams KL, et al. Staphylococcus Aureus Produces Pain Through Pore-Forming Toxins and Neuronal TRPV1 That Is Silenced by QX-314. Nat Commun (2018) 9(1):37. doi: 10.1038/s41467-017-02448-6

36. Yang NJ, Neel DV, Deng L, Heyang M, Kennedy-Curran A, Tong VS, et al. Nociceptive Sensory Neurons Mediate Inflammation Induced by Bacillus Anthracis Edema Toxin. Front Immunol (2021) 12:642373. doi: 10.3389/ fimmu.2021.642373

37. Ruhl CR, Pasko BL, Khan HS, Kindt LM, Stamm CE, Franco LH, et al. Mycobacterium Tuberculosis Sulfolipid-1 Activates Nociceptive Neurons and Induces Cough. Cell (2020) 181(2):293-305.e11. doi: 10.1016/ j.cell.2020.02.026

38. Zheng Y, Liu P, Bai L, Trimmer JS, Bean BP, Ginty DD. Deep Sequencing of Somatosensory Neurons Reveals Molecular Determinants of Intrinsic Physiological Properties. Neuron (2019) 103(4):598-616.e7. doi: 10.1016/ j.neuron.2019.05.039

39. Donnelly CR, Jiang C, Andriessen AS, Wang K, Wang Z, Ding H, et al. STING Controls Nociception via Type I Interferon Signalling in Sensory Neurons. Nature (2021) 591(7849):275-80. doi: 10.1038/s41586020-03151-1

40. Rehwinkel J, Gack MU. RIG-I-Like Receptors: Their Regulation and Roles in RNA Sensing. Nat Rev Immunol (2020) 20(9):537-51. doi: 10.1038/s41577-020-0288-3

41. Rehwinkel J, Tan CP, Goubau D, Schulz O, Pichlmair A, Bier K, et al. RIG-I Detects Viral Genomic RNA During Negative-Strand RNA Virus Infection. Cell (2010) 140(3):397-408. doi: 10.1016/j.cell.2010.01.020

42. Yoneyama M, Kikuchi M, Natsukawa T, Shinobu N, Imaizumi T, Miyagishi $\mathrm{M}$, et al. The RNA Helicase RIG-I has an Essential Function in DoubleStranded RNA-Induced Innate Antiviral Responses. Nat Immunol (2004) 5 (7):730-7. doi: 10.1038/ni1087

43. Kato H, Takeuchi O, Sato S, Yoneyama M, Yamamoto M, Matsui K, et al. Differential Roles of MDA5 and RIG-I Helicases in the Recognition of RNA Viruses. Nature (2006) 441(7089):101-5. doi: 10.1038/nature04734

44. Li J, Liu Y, Zhang X. Murine Coronavirus Induces Type I Interferon in Oligodendrocytes Through Recognition by RIG-I and MDA5. J Virol (2010) 84(13):6472-82. doi: 10.1128/JVI.00016-10

45. Shaw MH, Reimer T, Kim Y-G, Nuñez G. NOD-Like Receptors (NLRs): Bona Fide Intracellular Microbial Sensors. Curr Opin Immunol (2008) 20 (4):377-82. doi: 10.1016/j.coi.2008.06.001

46. Jung H, Toth PT, White FA, Miller RJ. Monocyte Chemoattractant Protein-1 Functions as a Neuromodulator in Dorsal Root Ganglia Neurons. J Neurochem (2007) 104(1):254-263. doi: 10.1111/j.1471-4159.2007.04969.x

47. Oetjen LK, Mack MR, Feng J, Whelan TM, Niu H, Guo CJ, et al. Sensory Neurons Co-Opt Classical Immune Signaling Pathways to Mediate Chronic Itch. Cell (2017) 171(1):217-28.e13. doi: 10.1016/j.cell.2017.08.006

48. Gonçalves WA, Rezende BM, de Oliveira MPE, Ribeiro LS, Fattori V, da Silva WN, et al. Sensory Ganglia-Specific TNF Expression Is Associated With Persistent Nociception After Resolution of Inflammation. Front Immunol (2020) 10:3120. doi: 10.3389/fimmu.2019.03120

49. Ebbinghaus M, Segond von Banchet G, Massier J, Gajda M, Bräuer R, Kress $\mathrm{M}$, et al. Interleukin-6-Dependent Influence of Nociceptive Sensory Neurons on Antigen-Induced Arthritis. Arthritis Res Ther (2015) 17(1):334. doi: 10.1186/s13075-015-0858-0

50. Binshtok AM, Wang H, Zimmermann K, Amaya F, Vardeh D, Shi L, et al. Nociceptors Are Interleukin-1 Sensors. J Neurosci (2008) 28(52):14062-73. doi: 10.1523/JNEUROSCI.3795-08.2008
51. Krukowski K, Eijkelkamp N, Laumet G, Hack CE, Li Y, Dougherty PM, et al. CD8+ T Cells and Endogenous IL-10 Are Required for Resolution of Chemotherapy-Induced Neuropathic Pain. J Neurosci (2016) 36 (43):11074-83. doi: 10.1523/JNEUROSCI.3708-15.2016

52. Laumet G, Bavencoffe A, Edralin JD, Huo X-J, Walters ET, Dantzer R, et al. Interleukin-10 Resolves Pain Hypersensitivity Induced by Cisplatin by Reversing Sensory Neuron Hyperexcitability. Pain (2020) 161(10):234452. doi: 10.1097/j.pain.0000000000001921

53. Shen K-F, Zhu H-Q, Wei X-H, Wang J, Li Y-Y, Pang R-P, et al. Interleukin10 Down-Regulates Voltage Gated Sodium Channels in Rat Dorsal Root Ganglion Neurons. Exp Neurol (2013) 247:466-75. doi: 10.1016/ j.expneurol.2013.01.018

54. Barragán-Iglesias P, Franco-Enzástiga U, Jeevakumar V, Shiers S, Wangzhou A, Granados-Soto V, et al. Type I Interferons Act Directly on Nociceptors to Produce Pain Sensitization: Implications for Viral Infection-Induced Pain. J Neurosci (2020) 40(18):3517-32. doi: 10.1523/JNEUROSCI.3055-19.2020

55. Talbot S, Abdulnour R-EE, Burkett PR, Lee S, Cronin SJF, Pascal MA, et al. Silencing Nociceptor Neurons Reduces Allergic Airway Inflammation. Neuron (2015) 87(2):341-54. doi: 10.1016/j.neuron.2015.06.007

56. Qu L, Zhang P, LaMotte RH, Ma C. Neuronal Fc-Gamma Receptor I Mediated Excitatory Effects of IgG Immune Complex on Rat Dorsal Root Ganglion Neurons. Brain Behav Immun (2011) 25(7):1399-407. doi: 10.1016/j.bbi.2011.04.008

57. Crosson T, Wang J-C, Doyle B, Merrison H, Balood M, Parrin A, et al. Fcer1-Expressing Nociceptors Trigger Allergic Airway Inflammation. J Allergy Clin Immunol (2021) 147(6):2330-42. doi: 10.1016/j.jaci.2020.12.644

58. Mathur S, Wang J-C, Seehus CR, Poirier F, Crosson T, Hsieh Y-C, et al. Nociceptor Neurons Promote IgE Class Switch in B Cells. JCI Insight (2021). doi: $10.1172 /$ jci.insight. 148510

59. Kollarik M, Ru F, Brozmanova M. Vagal Afferent Nerves With the Properties of Nociceptors. Auton Neurosci (2010) 153(1-2):12-20. doi: 10.1016/j.autneu.2009.08.001

60. Canning BJ, Chang AB, Bolser DC, Smith JA, Mazzone SB, McGarvey L, et al. Anatomy and Neurophysiology of Cough. Chest (2014) 146:1633-48. doi: 10.1378/chest.14-1481

61. Kollarik M, Ru F, Undem BJ. Acid-Sensitive Vagal Sensory Pathways and Cough. Pulm Pharmacol Ther (2007) 20(4):402-11. doi: 10.1016/ j.pupt.2006.11.010

62. Polverino M, Polverino F, Fasolino M, Andò F, Alfieri A, De Blasio F. Anatomy and Neuro-Pathophysiology of the Cough Reflex ArcMultidiscip. Respir Med (2012) 7(1):5. doi: 10.1186/2049-6958-7-5

63. Higgs R, Higgins SC, Ross PJ, Mills KHG. Immunity to the Respiratory Pathogen Bordetella Pertussis. Mucosal Immunol (2012) 5(5):485-500. doi: 10.1038/mi.2012.54

64. Shubayev VI, Kato K, Myers RR. Cytokines in Pain. Boca Raton (FL): CRC Press/Taylor \& Francis (2010).

65. Schaible H-G. Nociceptive Neurons Detect Cytokines in Arthritis. Arthritis Res Ther (2014) 16(5):470. doi: 10.1186/s13075-014-0470-8

66. Wallrapp A, Riesenfeld SJ, Burkett PR, Abdulnour R-EE, Nyman J, Dionne D, et al. The Neuropeptide NMU Amplifies ILC2-Driven Allergic Lung Inflammation. Nature (2017) 549(7672):351-6. doi: 10.1038/nature24029

67. Wallrapp A, Burkett PR, Riesenfeld SJ, Kim S-J, Christian E, Abdulnour REE, et al. Calcitonin Gene-Related Peptide Negatively Regulates AlarminDriven Type 2 Innate Lymphoid Cell Responses. Immunity (2019) 51 (4):709-23.e6. doi: 10.1016/j.immuni.2019.09.005

68. Perner C, Flayer CH, Zhu X, Aderhold PA, Dewan ZNA, Voisin T, et al. Substance P Release by Sensory Neurons Triggers Dendritic Cell Migration and Initiates the Type-2 Immune Response to Allergens. Immunity (2020) 53(5):1063-77.e7. doi: 10.1016/j.immuni.2020.10.001

69. Serhan N, Basso L, Sibilano R, Petitfils C, Meixiong J, Bonnart C, et al. House Dust Mites Activate Nociceptor-Mast Cell Clusters to Drive Type 2 Skin Inflammation. Nat Immunol (2019) 20(11):1435-43. doi: 10.1038/s41590019-0493-z

70. Hoeffel G, Debroas G, Roger A, Rossignol R, Gouilly J, Laprie C, et al. Sensory Neuron-Derived TAFA4 Promotes Macrophage Tissue Repair Functions. Nature (2021) 594:94-9. doi: 10.1038/s41586-021-03563-7

71. Nagashima H, Mahlakõiv T, Shih H-Y, Davis FP, Meylan F, Huang Y, et al. Neuropeptide CGRP Limits Group 2 Innate Lymphoid Cell Responses and 
Constrains Type 2 Inflammation. Immunity (2019) 51(4):682-95.e6. doi: 10.1016/j.immuni.2019.06.009

72. Cohen JA, Edwards TN, Liu AW, Hirai T, Jones MR, Wu J, et al. Cutaneous TRPV1+ Neurons Trigger Protective Innate Type 17 Anticipatory Immunity. Cell (2019) 178(4):919-32.e14. doi: 10.1016/j.cell.2019.06.022

73. Kashem SW, Riedl MS, Yao C, Honda CN, Vulchanova L, Kaplan DH. Nociceptive Sensory Fibers Drive Interleukin-23 Production From CD301b+ Dermal Dendritic Cells and Drive Protective Cutaneous Immunity. Immunity (2015) 43(3):515-26. doi: 10.1016/j.immuni.2015.08.016

74. Baral P, Umans BD, Li L, Wallrapp A, Bist M, Kirschbaum T, et al. Nociceptor Sensory Neurons Suppress Neutrophil and $\gamma \delta$ T Cell Responses in Bacterial Lung Infections and Lethal Pneumonia. Nat Med (2018) 24:417-26. doi: 10.1038/nm.4501

75. Pinho-Ribeiro FA, Baddal B, Haarsma R, O'Seaghdha M, Yang NJ, Blake KJ, et al. Blocking Neuronal Signaling to Immune Cells Treats Streptococcal Invasive Infection. Cell (2018) 173(5):1083-97.e22. doi: 10.1016/ j.cell.2018.04.006

76. Czepielewski RS, Porto BN, Rizzo LB, Roesler R, Abujamra AL, Pinto LG, et al. Gastrin-Releasing Peptide Receptor (GRPR) Mediates Chemotaxis in Neutrophils. Proc Natl Acad Sci (2012) 109(2):547-52. doi: 10.1073/ pnas. 1110996109

77. Kanashiro A, Hiroki CH, da Fonseca DM, Birbrair A, Ferreira RG, Bassi GS, et al. The Role of Neutrophils in Neuro-Immune Modulation. Pharmacol Res (2020) 151:104580. doi: 10.1016/j.phrs.2019.104580

78. Filtjens J, Roger A, Quatrini L, Wieduwild E, Gouilly J, Hoeffel G, et al. Nociceptive Sensory Neurons Promote CD8 T Cell Responses to HSV-1 Infection. Nat Commun (2021) 12(1):2936. doi: 10.1038/s41467-021-22841-6

79. Patil MJ, Ru F, Sun H, Wang J, Kolbeck RR, Dong X, et al. Acute Activation of Bronchopulmonary Vagal Nociceptors by Type I Interferons. J Physiol (2020) 598(23):5541-54. doi: 10.1113/JP280276

80. Shiers S, Ray PR, Wangzhou A, Sankaranarayanan I, Tatsui CE, Rhines LD, et al. ACE2 and SCARF Expression in Human Dorsal Root Ganglion Nociceptors: Implications for SARS-CoV-2 Virus Neurological Effects. Pain (2020) 161 (11):2494-501. doi: 10.1097/j.pain.0000000000002051

81. Robinot R, Hubert M, de Melo GD, Lazarini F, Bruel T, Smith N, et al. SARSCoV-2 Infection Induces the Dedifferentiation of Multiciliated Cells and Impairs Mucociliary Clearance. Nat Commun (2021) 12(1):4354. doi: 10.1038/s41467-021-24521-x

82. Liao M, Liu Y, Yuan J, Wen Y, Xu G, Zhao J, et al. Single-Cell Landscape of Bronchoalveolar Immune Cells in Patients With COVID-19. Nat Med (2020) 26(6):842-4. doi: 10.1038/s41591-020-0901-9

83. Blanco-Melo D, Nilsson-Payant BE, Liu W-C, Uhl S, Hoagland D, Møller R, et al. Imbalanced Host Response to SARS-CoV-2 Drives Development of COVID-19. Cell (2020) 181(5):1036-1045.e9. doi: 10.1016/j.cell.2020.04.026

84. Hadjadj J, Yatim N, Barnabei L, Corneau A, Boussier J, Smith N, et al. Impaired Type I Interferon Activity and Inflammatory Responses in Severe COVID-19 Patients. Science (80-) (2020) 369(6504):718-24. doi: 10.1126/ science.abc6027

85. Matschke J, Lütgehetmann M, Hagel C, Sperhake JP, Schröder AS, Edler C, et al. Neuropathology of Patients With COVID-19 in Germany: A PostMortem Case Series. Lancet Neurol (2020) 19(11):919-29. doi: 10.1016/ S1474-4422(20)30308-2

86. Jiang R-D, Liu M-Q, Chen Y, Shan C, Zhou Y-W, Shen X-R, et al. Pathogenesis of SARS-CoV-2 in Transgenic Mice Expressing Human Angiotensin-Converting Enzyme 2. Cell (2020) 182(1):50-8.e8. doi: $10.1016 /$ j.cell.2020.05.027

87. Ramani A, Müller L, Ostermann PN, Gabriel E, Abida-Islam P, MüllerSchiffmann A, et al. SARS -CoV-2 Targets Neurons of 3D Human Brain Organoids. EMBO J (2020) 39(20):e106230. doi: 10.15252/embj.2020106230

88. Ray PR, Wangzhou A, Ghneim N, Yousuf MS, Paige C, Tavares-Ferreira D, et al. A Pharmacological Interactome Between COVID-19 Patient Samples and Human Sensory Neurons Reveals Potential Drivers of Neurogenic Pulmonary Dysfunction. Brain Behav Immun (2020) 89:559-68. doi: 10.1016/j.bbi.2020.05.078

89. Gu J, Gong E, Zhang B, Zheng J, Gao Z, Zhong Y, et al. Multiple Organ Infection and the Pathogenesis of SARS. J Exp Med (2005) 202(3):415-24. doi: $10.1084 /$ jem.20050828
90. McCray PB, Pewe L, Wohlford-Lenane C, Hickey M, Manzel L, Shi L, et al. Lethal Infection of K18- Hace2 Mice Infected With Severe Acute Respiratory Syndrome Coronavirus. J Virol (2007) 81(2):813-21. doi: 10.1128/ JVI.02012-06

91. Netland J, Meyerholz DK, Moore S, Cassell M, Perlman S. Severe Acute Respiratory Syndrome Coronavirus Infection Causes Neuronal Death in the Absence of Encephalitis in Mice Transgenic for Human Ace2. J Virol (2008) 82(15):7264-75. doi: 10.1128/JVI.00737-08

92. Lau K-K, Yu W-C, Chu C-M, Lau S-T, Sheng B, Yuen K-Y. Possible Central Nervous System Infection by SARS Coronavirus. Emerg Infect Dis (2004) 10 (2):342-4. doi: 10.3201/eid1002.030638

93. Hung ECW, Chim SSC, Chan PKS, Tong YK, Ng EKO, Chiu RWK, et al. Detection of SARS Coronavirus RNA in the Cerebrospinal Fluid of a Patient With Severe Acute Respiratory Syndrome. Clin Chem (2003) 49(12):2108-9. doi: 10.1373/clinchem.2003.025437

94. Yamashita M, Yamate M, Li G-M, Ikuta K. Susceptibility of Human and Rat Neural Cell Lines to Infection by SARS-Coronavirus. Biochem Biophys Res Commun (2005) 334(1):79-85. doi: 10.1016/j.bbrc.2005.06.061

95. DeDiego ML, Pewe L, Alvarez E, Rejas MT, Perlman S, Enjuanes L. Pathogenicity of Severe Acute Respiratory Coronavirus Deletion Mutants in hACE-2 Transgenic Mice. Virology (2008) 376(2):379-89. doi: 10.1016/ j.virol.2008.03.005

96. Nieto-Torres JL, DeDiego ML, Verdiá-Báguena C, Jimenez-Guardeño JM, Regla-Nava JA, Fernandez-Delgado R, et al. Severe Acute Respiratory Syndrome Coronavirus Envelope Protein Ion Channel Activity Promotes Virus Fitness and Pathogenesis. PloS Pathog (2014) 10(5):e1004077. doi: 10.1371/journal.ppat.1004077

97. DeDiego ML, Álvarez E, Almazán F, Rejas MT, Lamirande E, Roberts A, et al. A Severe Acute Respiratory Syndrome Coronavirus That Lacks the E Gene Is Attenuated In Vitro and In Vivo. J Virol (2007) 81(4):1701-13. doi: 10.1128/JVI.01467-06

98. Doty RL. The Mechanisms of Smell Loss After SARS-CoV-2 Infection. Lancet Neurol (2021) 20(9):693-5. doi: 10.1016/S1474-4422(21)00202-7

99. de Melo GD, Lazarini F, Levallois S, Hautefort C, Michel V, Larrous F, et al. COVID-19-Related Anosmia Is Associated With Viral Persistence and Inflammation in Human Olfactory Epithelium and Brain Infection in Hamsters. Sci Transl Med (2021) 13(596):eabf8396. doi: 10.1126/ scitranslmed.abf8396

100. Brann DH, Tsukahara T, Weinreb C, Lipovsek M, Van den Berge K, Gong B, et al. Non-Neuronal Expression of SARS-CoV-2 Entry Genes in the Olfactory System Suggests Mechanisms Underlying COVID-19-Associated Anosmia. Sci $A d v$ (2020) 6(31):eabc5801. doi: 10.1126/sciadv.abc5801

101. Cantuti-Castelvetri L, Ojha R, Pedro LD, Djannatian M, Franz J, Kuivanen S, et al. Neuropilin-1 Facilitates SARS-CoV-2 Cell Entry and Infectivity. Science (80-) (2020) 370(6518):856-60. doi: 10.1126/science.abd2985

102. Xia B, Shen X, He Y, Pan X, Liu F-L, Wang Y, et al. SARS-CoV-2 Envelope Protein Causes Acute Respiratory Distress Syndrome (ARDS)-Like Pathological Damages and Constitutes an Antiviral Target. Cell Res (2021) 31(8):847-60. doi: 10.1038/s41422-021-00519-4

103. Fernández-de-las-Peñas $C$, Guijarro C, Plaza-Canteli S, Hernández-Barrera V, Torres-Macho J. Prevalence of Post-COVID-19 Cough One Year After SARS-CoV-2 Infection: A Multicenter Study. Lung (2021) 199(3):249-53. doi: 10.1007/s00408-021-00450-w

104. Nalbandian A, Sehgal K, Gupta A, Madhavan MV, McGroder C, Stevens JS, et al. Post-Acute COVID-19 Syndrome. Nat Med (2021) 27(4):601-15. doi: 10.1038/s41591-021-01283-z

105. Li H, Leong FY, Xu G, Kang CW, Lim KH, Tan BH, et al. Airborne Dispersion of Droplets During Coughing: A Physical Model of Viral Transmission. Sci Rep (2021) 11(1):4617. doi: 10.1038/s41598-021-84245-2

106. Zheng M, Karki R, Williams EP, Yang D, Fitzpatrick E, Vogel P, et al. TLR2 Senses the SARS-CoV-2 Envelope Protein to Produce Inflammatory Cytokines. Nat Immunol (2021) 22(7):829-38. doi: 10.1038/s41590-02100937-x

107. Del Valle DM, Kim-Schulze S, Huang H-H, Beckmann ND, Nirenberg S, Wang B, et al. An Inflammatory Cytokine Signature Predicts COVID-19 Severity and Survival. Nat Med (2020) 26(10):1636-43. doi: 10.1038/s41591020-1051-9 
108. Bastard P, Rosen LB, Zhang Q, Michailidis E, Hoffmann H-H, Zhang Y, et al. Autoantibodies Against Type I IFNs in Patients With Life-Threatening COVID19. Science (80-) (2020) 370(6515):eabd4585. doi: 10.1126/science.abd4585

109. Bax HJ, Keeble AH, Gould HJ. Cytokinergic IgE Action in Mast Cell Activation. Front Immunol (2012) 3:229. doi: 10.3389/fimmu.2012.00229

110. Farmani AR, Mahdavinezhad F, Moslemi R, Mehrabi Z, Noori A, Kouhestani M, et al. Anti-IgE Monoclonal Antibodies as Potential Treatment in COVID-19. Immunopharmacol Immunotoxicol (2021) 43 (3):259-64. doi: 10.1080/08923973.2021.1925906

111. Rui Y, Su J, Shen S, Hu Y, Huang D, Zheng W, et al. Unique and Complementary Suppression of cGAS-STING and RNA Sensing- Triggered Innate Immune Responses by SARS-CoV-2 Proteins. Signal Transduction Targeting Ther (2021) 6(1):123. doi: 10.1038/s41392-021-00515-5

112. Li M, Ferretti M, Ying B, Descamps H, Lee E, Dittmar M, et al. Pharmacological Activation of STING Blocks SARS-CoV-2 Infection. Sci Immunol (2021) 6(59):eabi9007. doi: 10.1126/sciimmunol.abi9007

113. Kanberg N, Ashton NJ, Andersson L-M, Yilmaz A, Lindh M, Nilsson S, et al. Neurochemical Evidence of Astrocytic and Neuronal Injury Commonly Found in COVID-19. Neurology (2020) 95(12):e1754-9. doi: 10.1212/ WNL.0000000000010111

114. Ameres M, Brandstetter S, Toncheva AA, Kabesch M, Leppert D, Kuhle J, et al. Association of Neuronal Injury Blood Marker Neurofilament Light Chain With Mild-to-Moderate COVID-19. J Neurol (2020) 267(12):3476-8. doi: 10.1007/s00415-020-10050-y

115. Nahama A, Ramachandran R, Cisternas AF, Ji H. The Role of Afferent Pulmonary Innervation in ARDS Associated With COVID-19 and Potential Use of Resiniferatoxin to Improve Prognosis: A Review. Med Drug Discov (2020) 5:100033. doi: 10.1016/j.medidd.2020.100033

116. Robertson CE. Could CGRP Antagonists Be Helpful in the Fight Against COVID-19? Headache J Head Face Pain (2020) 60(7):1450-2. doi: 10.1111/ head. 13853

117. Ochoa-Callejero L, García-Sanmartín J, Villoslada-Blanco P, Íñiguez M, Pérez-Matute P, Pujadas E, et al. Circulating Levels of Calcitonin GeneRelated Peptide Are Lower in COVID-19 Patients. J Endocr Soc (2021) 5(3): bvaa199. doi: 10.1210/jendso/bvaa199

118. Wanner SP, Garami A, Pakai E, Oliveira DL, Gavva NR, Coimbra CC, et al. Aging Reverses the Role of the Transient Receptor Potential Vanilloid-1 Channel in Systemic Inflammation From Anti-Inflammatory to Proinflammatory. Cell Cycle (2012) 11(2):343-9. doi: 10.4161/cc.11.2.18772

119. García D, Brazal S, Rodríguez A, Prat A, Vassena R. Knowledge of AgeRelated Fertility Decline in Women: A Systematic Review. Eur J Obstet Gynecol Reprod Biol (2018) 230:109-18. doi: 10.1016/j.ejogrb.2018.09.030

120. Denic A, Glassock RJ, Rule AD. Structural and Functional Changes With the Aging Kidney. Adv Chronic Kidney Dis (2016) 23(1):19-28. doi: 10.1053/ j.ackd.2015.08.004

121. Tan JL, Eastment JG, Poudel A, Hubbard RE. Age-Related Changes in Hepatic Function: An Update on Implications for Drug Therapy. Drugs Aging (2015) 32(12):999-1008. doi: 10.1007/s40266-015-0318-1

122. Fliers E, Swaab DF. Chapter 9 Neuropeptide Changes in Aging and Alzheimer's Disease. Elsevier (1986) 70:141-52.

123. Petralia RS, Mattson MP, Yao PJ. Communication Breakdown: The Impact of Ageing on Synapse Structure. Ageing Res Rev (2014) 14:31-42. doi: 10.1016/j.arr.2014.01.003

124. Chen D, Huang Y, Shi Z, Li J, Zhang Y, et al. Demyelinating Processes in Aging and Stroke in the Central Nervous System and the Prospect of Treatment Strategy. CNS Neurosci Ther (2020) 26(12):1219-29. doi: 10.1111/cns.13497

125. Riera CE, et al. TRPV1 Pain Receptors Regulate Longevity and Metabolism by Neuropeptide Signaling. Cell (2014) 157(5):1023-36. doi: 10.1016/j.cell.2014.03.051

126. Lautenbacher S, Peters JH, Heesen M, Scheel J, Kunz M. Age Changes in Pain Perception: A Systematic-Review and Meta-Analysis of Age Effects on Pain and Tolerance Thresholds. Neurosci Biobehav Rev (2017) 75:104-13. doi: 10.1016/j.neubiorev.2017.01.039

127. Daguet I, Bergeron-Vezina K, Harvey M-P, Martel M, Coulombe-Leveque A, Leonard G. Decreased Initial Peak Pain Sensation With Aging: A Psychophysical Study. J Pain Res (2020) 13:2333-41. doi: 10.2147/JPR.S257791

128. Sharma G, Goodwin J. Effect of Aging on Respiratory System Physiology and Immunology. Clin Interv Aging (2006) 1(3):253-60. doi: 10.2147/ciia.2006.1.3.253
129. Thomas ET, Guppy M, Straus SE, Bell KJL, Glasziou P. Rate of Normal Lung Function Decline in Ageing Adults: A Systematic Review of Prospective Cohort Studies. BMJ Open (2019) 9(6):e028150. doi: 10.1136/bmjopen-2018-028150

130. Kovacs E, Lowery E, Kuhlmann E, Brubaker A. The Aging Lung. Clin Interv Aging (2013), 1489. doi: 10.2147/CIA.S51152

131. Franceschi C, Garagnani P, Parini P, Giuliani C, Santoro A. Inflammaging: A New Immune-Metabolic Viewpoint for Age-Related Diseases. Nat Rev Endocrinol (2018) 14(10):576-90. doi: 10.1038/s41574-018-0059-4

132. Barkaway A, Rolas L, Joulia R, Bodkin J, Lenn T, Owen-Woods C, et al. AgeRelated Changes in the Local Milieu of Inflamed Tissues Cause Aberrant Neutrophil Trafficking and Subsequent Remote Organ Damage. Immunity (2021) 54:1494-510. doi: 10.1016/j.immuni.2021.04.025

133. Brandenberger C, Mühlfeld C. Mechanisms of Lung Aging. Cell Tissue Res (2017) 367(3):469-80. doi: 10.1007/s00441-016-2511-x

134. Xi Y, Shao F, Bai X-Y, Cai G, Lv Y, Chen X. Changes in the Expression of the Toll-Like Receptor System in the Aging Rat Kidneys. PloS One (2014) 9(5): e96351. doi: 10.1371/journal.pone.0096351

135. Nyugen J, Agrawal S, Gollapudi S, Gupta S. Impaired Functions of Peripheral Blood Monocyte Subpopulations in Aged Humans. J Clin Immunol (2010) 30 (6):806-13. doi: 10.1007/s10875-010-9448-8

136. Shaw AC, Goldstein DR, Montgomery RR. Age-Dependent Dysregulation of Innate Immunity. Nat Rev Immunol (2013) 13(12):875-87. doi: 10.1038/ nri3547

137. Kallo I, Kalamatianos T, Piggins HD, Coen CW. Ageing and the Diurnal Expression of mRNAs for Vasoactive Intestinal Peptide and for the VPAC2 and PAC1 Receptors in the Suprachiasmatic Nucleus of Male Rats. J Neuroendocrinol (2004) 16(9):758-66. doi: 10.1111/j.1365-2826. 2004.01232.x

138. Song W-J, Won H-K, An J, Kang S-Y, Jo E-J, Chang Y-S, et al. Chronic Cough in the Elderly. Pulm Pharmacol Ther (2019) 56:63-8. doi: 10.1016/ j.pupt.2019.03.010

139. Calvo-Rodríguez M, de la Fuente C, García-Durillo M, García-Rodríguez C, Villalobos C, Núñez L. Aging and Amyloid $\beta$ Oligomers Enhance TLR4 Expression, LPS-Induced Ca2+ Responses, and Neuron Cell Death in Cultured Rat Hippocampal Neurons. J Neuroinflamm (2017) 14(1):24. doi: 10.1186/s12974-017-0802-0

140. Hasegawa S, Inoue T, Inagi R. Neuroimmune Interactions and Kidney Disease. Kidney Res Clin Pract (2019) 38(3):282-94. doi: 10.23876/ j.krcp. 19.014

141. Yamada M, Ichinose M. The Cholinergic Pathways in Inflammation: A Potential Pharmacotherapeutic Target for COPD. Front Pharmacol (2018) 9:1426. doi: 10.3389/fphar.2018.01426

142. Zimmermann P, Curtis N. Why Is COVID-19 Less Severe in Children? A Review of the Proposed Mechanisms Underlying the Age-Related Difference in Severity of SARS-CoV-2 Infections. Arch Dis Child (2021) 106(5):429-39. doi: 10.1136/archdischild-2020-320338

143. Baker SA, Kwok S, Berry GJ, Montine TJ. Angiotensin-Converting Enzyme 2 (ACE2) Expression Increases With Age in Patients Requiring Mechanical Ventilation. PloS One (2021) 16(2):e0247060. doi: 10.1371/journal. pone. 0247060

Conflict of Interest: The authors declare that the research was conducted in the absence of any commercial or financial relationships that could be construed as a potential conflict of interest.

Publisher's Note: All claims expressed in this article are solely those of the authors and do not necessarily represent those of their affiliated organizations, or those of the publisher, the editors and the reviewers. Any product that may be evaluated in this article, or claim that may be made by its manufacturer, is not guaranteed or endorsed by the publisher.

Copyright () 2021 Hiroki, Sarden, Hassanabad and Yipp. This is an open-access article distributed under the terms of the Creative Commons Attribution License (CC BY). The use, distribution or reproduction in other forums is permitted, provided the original author(s) and the copyright owner(s) are credited and that the original publication in this journal is cited, in accordance with accepted academic practice. No use, distribution or reproduction is permitted which does not comply with these terms. 